\title{
O CURRÍCULO E O ESTÁGIO SUPERVISIONADO NA FORMAÇÃO DO PROFESSOR DE EDUCAÇÃO FÍSICA NA AMAZÔNIA
}

\author{
Josué José de Carvalho Filho104 \\ Tânia Suely Azevedo Brasileiro 105
}

\section{RESUMO}

Este artigo e parte de uma dissertação de mestrado e traz reflexões sobre o Estágio Curricular Supervisionado na Amazônia. Com isso, o objetivo consistiu em analisar o estágio curricular supervisionado na formação do professor de Educação Física em uma IFES da região norte, levando em consideração seu currículo. A pesquisa foi descritiva/qualitativa, a partir de um estudo de caso no curso de Educação Física da UNIR. O marco teórico adotado dialogou com autores como: Bianchi, Alvarenga e Bianchi (2009), Contreras (2012), D'Avila (2013), Dourado (2015), Libâneo (2013), Pimenta (2012a, 2012b), Pimenta e Lima (2011) e Veiga (2010, 2004), entre outros que discutem a temática abordada. Os participantes e instrumentos do estudo foram dois docentes, um deles foi coordenador de curso e o outro o supervisor de estagio, e quatorze discentes, sendo aplicação de entrevista aos primeiros e questionário semiestruturado com os segundos. O tratamento e discussão das informações coletadas se deram à luz da análise de conteúdos de Bardin (2009). Os resultados revelaram que o estágio na formação do professor de Educação Física contribui para a mobilização de saberes e implica na decisão em "ser ou não ser" um professor. Trata-se, portanto, de uma proposta de estágio realimentada pelos sujeitos que vivem a teoria e a prática a partir do currículo vivido, pela profissão exercida e pelo compromisso com o futuro campo de trabalho.

Palavras-chave: Estágio Curricular Supervisionado. Educação Física na Amazônia. Currículo.

\section{THE CURRICULUM AND THE SUPERVISED INTERNSHIP IN PHYSICAL EDUCATION}

\section{TEACHER TRAINING IN THE AMAZON}

\begin{abstract}
This article is part of a dissertation and reflects on the Supervised Curricular Teacher Training in the Amazon. Thus, its objective is to analyze the supervised curricular

\footnotetext{
104 Mestre em Educação PPGE/UNIR. Docente da Faculdade Metropolitana de Porto VelhoRO. Membro/pesquisador do grupo de Pesquisa Práxis/UNIR. E-mail: josuecarvalho.filho@gmail.com

105 Pós-doutora em Psicologia pelo Instituto de Psicologia da Universidade de São Paulo. Doutora em Educação pela Universidad Rovira i Virgili/Espanha. Docente do Programa de Pós-graduação em Educação da Universidade Federal do Oeste do Pará. E-mail: brasileirotania@gmail.com
} 
teacher training in the formation of the Physical Education teacher in a Federal Institution of the north region, taking into consideration its curriculum. The research was descriptive/qualitative, based on a case study in the Physical Education Course of UNIR. The theoretical framework adopted dialogued with authors such as: Bianchi, Alvarenga and Bianchi (2009), Contreras (2012), D'Avila (2013), Dourado (2015), Libâneo (2013), Pimenta (2012a, 2012b), Pimenta and Lima (2011) and Veiga (2010, 2004), among others that discuss the subject. The participants and instruments in the study were two teachers, one of them was the coordinator of the course and the other one was the supervisor of the teacher training, and fourteen students, when an interview was applied to the first ones along with a semi-structured questionnaire to the last ones. The treatment and discussion of the information collected came from the analysis of contents as in Bardin (2009). The results revealed that the teacher training in the formation of the Physical Education teacher contributes to the mobilization of knowledge and implies in the decision to "be or not be" a teacher. Therefore, it is a proposal for teacher apprenticeship refed by individuals who live the theory and practice from the curriculum, experienced by occupation and by commitment to the future field of work.

Keyword: Supervised Curricular Internship. Physical Education in the Amazon. Curriculum.

\section{INTRODUÇÃO}

Este artigo apresenta $\bigcirc$ Estágio Curricular Supervisionado na formação do professor de Educação Física a partir do currículo formal (escrito) e real (vivido), ambos instituídos pela legislação e documentos norteadores para os cursos de licenciatura no país, e pelos sujeitos envolvidos no processo de formação inicial na realidade estudada, bem como pelos teóricos: Bianchi, Alvarenga e Bianchi (2009), Contreras (2012), D'Avila (2013), Dourado (2015), Libâneo (2013), Pimenta (2012), Pimenta e Lima (2011) e Veiga $(2010,2004)$, entre outros que discutem a temática abordada.

A relevância dessa investigação está em permitir refletir sobre a formação docente nos cursos de licenciatura em Educação Física na Amazônia. Decorre daí a questão problematizadora do estudo como o estágio curricular supervisionado a partir do currículo formal e real contribui para a formação do professor de Educação Física?

Dessa problemática emergiu o objetivo deste estudo, qual seja, analisar o estágio curricular supervisionado na formação do professor de Educação Física em uma IFES da região norte, levando em consideração seu 
currículo. Os caminhos metodológicos foram delineados por uma pesquisa descritiva, de abordagem qualitativa, a partir de um estudo de caso no curso de Educação Física da UNIR. Este estudo foi realizado em dois momentos: 1. Pesquisa bibliográfica e documental; 2. Pesquisa de campo. Os participantes foram dois docentes e quatorze discentes. Os instrumentos de coleta de dados foram um roteiro de entrevista aplicado aos docentes e questionário semiestruturado aos discentes. A discussão ocorreu à luz da análise de conteúdos em Bardin (2009).

Nas considerações finais, o estágio curricular supervisionado não se consolida por organismos isolados. Essa consolidação depende da integração exercida pelos documentos norteadores, currículo prescrito e experienciado, alunos em formação, professores formadores, e gestores do curso. A organização desse espaço implica na proposta de estágio realimentado pelos sujeitos que vivem a teoria e o domínio da prática pedagógica nos cotidianos educativos no chão da escola.

\section{O CURRÍCULO COMO ALICERCE DO ESTÁGIO CURRICULAR SUPERVISIONADO NA FORMAÇÃO EM EDUCAÇÃO FÍSICA}

Ao refletirmos sobre o estágio curricular supervisionado na formação do professor de Educação Física faz-se necessário trazer o currículo formal, ou seja, os documentos legais que norteiam a organização curricular dos cursos de licenciatura em Educação Física.

Esse recorte encontra-se delineado a partir dos saberes docentes e a relação teoria prática evidenciados no estágio curricular supervisionado. Isso decorre no contexto da problemática vivenciada pelas instituições de ensino superior na formação dos futuros professores no Brasil, conforme citado por D'Ávila (2013), quando destaca a necessidade de investigarmos sobre as relações de currículo e profissionalização docente e, especialmente, o professor da Educação Básica. 
Por esse prisma, entendemos que não é simples colocar em prática e articular os componentes curriculares, porém, é necessário saber que

\begin{abstract}
A falta então de um currículo interdisciplinar que configure uma formação em rede tem ocasionado o fracionamento do conhecimento profissional propiciado ao estudante de licenciatura. De modo que o mesmo conclui curso sem uma visão integrada de docência e pesquisa, por exemplo, ou entre o que estudou no currículo do seu curso e o que precisa praticar como professor da educação básica. O cenário continua problemático, pois, as licenciaturas em seus diferentes cursos parecem afigurar-se como ilhas localizadas num grande arquipélago. (D'ÁVILA, 2013, p. 25).
\end{abstract}

Diante dessa realidade apontada pela autora, como um problema visualizado nas matrizes curriculares dos cursos de formação de professores, é possível perceber que em algumas realidades, o currículo formal diverge do real no dia-a-dia no processo de formação. Trazemos Libâneo (2013) para conceituar essas duas dimensões de currículo:

Currículo formal refere-se ao currículo estabelecido pelos sistemas ensino ou instituição educacional. É o currículo legal expresso em diretrizes curriculares, objetivos e conteúdo das áreas ou disciplinas de estudo. O currículo formal ou oficial é aquele conjunto de diretrizes normativas prescritas institucionalmente.

Currículo real é o currículo que, de fato, acontece na sala de aula em decorrência de um projeto pedagógico e dos planos de ensino. É a execução de um plano, é a efetivação do que foi planejado, mesmo que nesse caminho do planejar e do executar aconteçam mudanças, intervenção da própria experiência dos professores, decorrentes dos seus valores, crenças, significados. É o currículo que sai da prática dos professores, da percepção e do uso que os professores fazem do currículo formal (LIBÂNEO, 2013, p. 142).

Nessa perspectiva, temos como foco analisar a organização do currículo formal (prescrito), instituído e normatizado pelos órgãos gestores da educação superior e, consequentemente, os documentos oficiais que norteiam os cursos de formação de professores no Brasil.

Com efeito, em 2015 foi publicada a Resolução CNE/CP 02/2015, que instituiu e trouxe uma nova configuração para os cursos de formação de professores. As Instituições de Ensino Superior (IES) brasileiras precisam atender o estabelecido na nova medida. 
Cumpre esclarecer que esse comando legal revogou as resoluções: CNE/CP n 2 de 26 de junho de 1997; CNE/CP n 1, de 30 de setembro de 1999; CNE/CP n 1, de 18 de fevereiro de 2002 e suas alterações; CNE/CP nº 2, de 19 de fevereiro de 2002 e suas alterações; Resolução $n^{\circ}$ 1, de 11 de fevereiro de 2009 e, ainda a Resolução n 3, de 7 de dezembro de 2012 (BRASIL, 2015).

Segundo Dourado (2015, p. 307), a resolução CNE/CP 02/2015, traz inúmeras considerações sobre a formação do licenciado e destaca:

[...] a concepção articulada de formação inicial e continuada, as novas DCNs definem que é fundamental que as instituições formadoras institucionalizem projeto de formação com identidade própria, em consonância com $\circ$ Plano de Desenvolvimento Institucional (PDI), o Projeto Pedagógico Institucional (PPI) e o Projeto Pedagógico de Curso (PPC).

Nessa direção, as novas DCNs definem que o(a) egresso(a) da formação inicial e continuada deverá possuir um repertório de informações e habilidades composto pela pluralidade de conhecimentos teóricos e práticos, resultado do projeto pedagógico e do percurso formativo vivenciado cuja consolidação virá do seu exercício profissional, fundamentado em princípios de interdisciplinaridade, contextualização, democratização, pertinência e relevância social, ética e sensibilidade afetiva e estética, de modo a lhe permitir: o conhecimento da instituição educativa; a pesquisa; atuação profissional no ensino, na gestão de processos educativos e na organização e gestão de instituições de educação básica.

Com a revogação das resoluções supracitadas, os cursos de licenciaturas, que antes eram integralizados em 3 anos por algumas IES, doravante terão a duração de 4 anos. Segundo Tojal (2015, 31-32),

No tocante à carga horária, esses cursos terão no mínimo, 3.200 (três mil e duzentas) horas de efetivo trabalho acadêmico, com duração de, no mínimo, 8 (oito) semestres ou 4 (quatro) anos, ficando assim dividida essa carga horária mínima: 1 - 400 (quatrocentas) horas de prática como componente curricular, distribuídas ao longo do processo formativo; II - 400 (quatrocentas) horas dedicadas ao estágio supervisionado, na área de formação e atuação exclusiva na educação básica e, se for o caso, conforme o projeto de curso da instituição, que deverá considerar e aplicar nessas horas de aprendizado prático, o reconhecimento das instituições de educação básica como espaços necessários à formação dos profissionais do magistério, III - pelo menos 2.200 (duas mil e duzentas) horas dedicadas às atividades formativas estruturadas pelos núcleos definidos nos incisos I e II do artigo 12 da Resolução, conforme o projeto de curso da instituição; IV - 200 (duzentas) horas de 
atividades teórico-práticas de aprofundamento em áreas específicas de interesse dos estudantes, conforme núcleo definido no inciso III do artigo 12 da Resolução, por meio da iniciação científica, da iniciação à docência, da extensão e da monitoria, entre outras, consoante o projeto de curso da instituição.

Em síntese, os cursos de licenciatura em todo o país terão que se adequar num prazo máximo de dois anos. Evidencia-se, também, que a expectativa do órgão gestor federal é que as IES formadoras de professores cumpram integralmente os procedimentos mencionados no sentido de aproximar o documento escrito à realidade do processo formativo. Entretanto, alguns cursos estão funcionando nos moldes da resolução CNE/CP 01 /2002, pois o prazo de implantação para cumprimento da Resolução CNEO2/2015 ainda está em vigor, ou seja, a mudança de fato e de direito acontecerá a partir de julho do ano de 2017.

$\mathrm{Na}$ área de Educação Física, temos a Resolução CNE/CES 07/2004 que instituiu as Diretrizes Curriculares Nacionais para o curso de graduação em Educação Física, em nível superior de graduação plena. Assim, estabelece orientações específicas para as duas áreas de atuação, ou seja, licenciatura e bacharelado (BRASIL, 2004).

Ambas as DCN, Resolução CNE/CP 02/2015 e CNE/CES 07/2004 norteiam a estruturação curricular dos cursos de formação de professores em Educação Física no Brasil. Com isso, cabe aprofundarmos um estudo documental, a partir do que está instituído nesses documentos norteadores a partir de uma reflexão sobre a relação do currículo formal e o real da IES e seu paralelo com os dispositivos legais.

Entretanto, é pertinente trazer a lume as palavras de Veiga (2010, p. 17).

Os licenciados realizam sua formação num contexto de educação superior que a caracteriza pela perda de sua identidade social e a transforma em uma instância administrativa, burocratizada e operacional. Dessa forma eles atuam obedecendo a um conjunto de regras e normas emanadas do poder público.

Seguindo de perto a crítica abordada pela autora colacionamos o artigo $4^{\circ}$ da resolução CNE/CES 07/2004: "O curso de graduação em 
Educação Física deverá assegurar uma formação generalista, humanista e crítica, qualificadora da intervenção acadêmico-profissional, fundamentada no rigor científico, na reflexão filosófica e na conduta ética" (BRASIL, 2004).

O artigo $7^{\circ}$, por tratar especificamente da organização curricular, a partir das unidades de conhecimentos específicas e ampliadas e suas respectivas dimensões. Esse mesmo dispositivo legal em seu parágrafo $3^{\circ}$ deixa a critério das IES a opção de incluir um ou mais núcleos temáticos de aprofundamento, determinando a utilização de até $20 \%$ da carga horária total, articulando as unidades de conhecimentos e de experiências no decorrer na formação inicial.

O parágrafo $4^{\circ}$ do artigo $7^{\circ}$ estabelece de forma contundente que as questões pertinentes às peculiaridades regionais, às identidades culturais, à educação ambiental, ao trabalho, às necessidades das pessoas portadoras de deficiência e de grupos e comunidades especiais. Já o artigo $8^{\circ}$ dessa mesma resolução anuncia claramente que, para o curso de formação de professores de Educação Básica, licenciatura em Educação Física, as unidades de conhecimentos específicos são permeadas pelas dimensões biológicas, sociais, culturais, didático-pedagógico, técnicoinstrumentais do movimento humano (BRASIL, 2004).

Assim, para que possamos entender a Resolução CNE/CES 07/2004, por meio dos artigos supracitados, apresentamos esquematicamente a estrutura para organização curricular nos cursos de Educação Física por meio de um mapa conceitual ilustrado a seguir: 
Organograma 1 - Organização do currículo para cursos de Educação Física segundo a resolução CNE/CES 07/2004

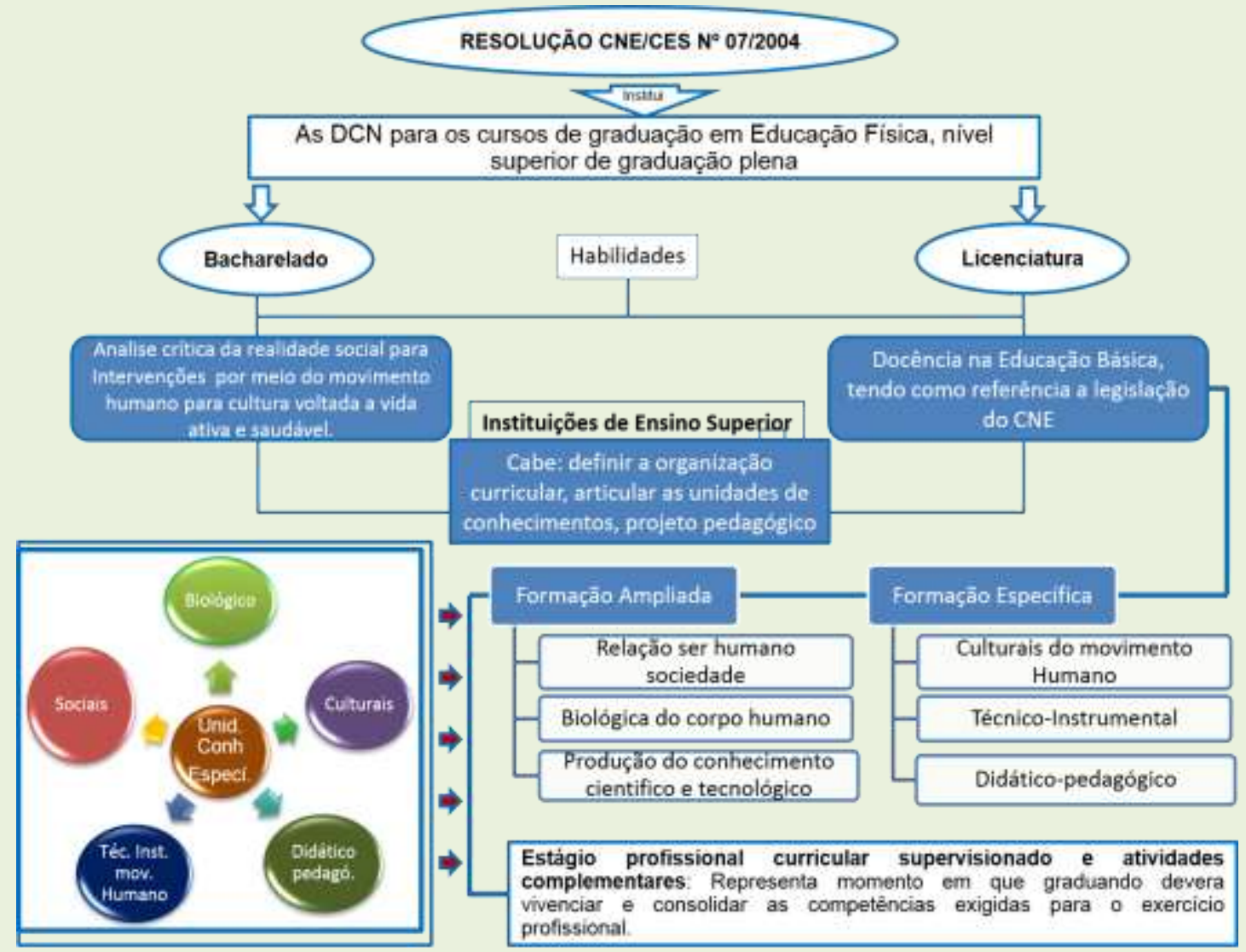

Fonte: Figura elaborada pelo autor com base na Res. CNE/CES 07/2004 (BRASIL, 2004).

Com base nessa ilustração, ficou evidente que as DCN indicam elementos pré-estabelecidos, os quais devem ser levados em consideração no momento da estruturação curricular dos cursos de Educação Física e apresenta princípios norteadores para a formação de professores da Educação Básica, como se fosse possível considerar que essas normas consigam motivar e mobilizar o preparo profissional somente a partir do que está escrito e instituído, uma vez que no contexto histórico Veiga (2004, p. 16) acrescenta quando chama atenção e reitera que "deveremos usar os princípios da flexibilidade e da autonomia, de modo a desenvolver identidades mais distantes da padronização burocrática, capazes de instituir e implementar projetos políticos-pedagógicos próprios".

Libâneo (2013, p. 77) destaca que: 
Ao se planejar o currículo e outras ações educativas de formação inicial e continuada de professores, as competências não podem ser reduzidas a meras habilidades a serem treinadas, nem tornadas instrumentos de competição entre as pessoas, como ocorreria numa perspectiva meramente economicista. Ao contrário, são requeridos conhecimentos, competências técnico metodológicas (domínio do processo de trabalho) e competências subjetivas e comunicativas (capacidade de estabelecer relações humanas, competências sóciocomunicativas, formas participativas), competências transformadoras.

De fato, o autor discorda da visão restrita ligada as habilidades, ao "saber fazer" de como as competências são trazidas nas DCN e defende a competência como "sinônimo de formação omnilateral (integral), formação politécnica, em que os profissionais desenvolvem capacidades subjetivas-intelectuais, física, sociais, estéticas, éticas e profissionais-visando a unidade, na ação humana, entre capacidades intelectuais e práticas" (LIBÂNEO, 2013, p. 76).

Conforme vimos mencionando, as DCN para formação de professores da Educação Básica como instituinte da estruturação e organização curricular nos cursos de licenciatura, ao nos reportamos ao autor supracitado, trazemos a lume o PPP do curso de Educação Física da Universidade Federal de Rondônia (UNIR, 2012), onde ficou evidenciado que $o$ referido documento foi pensado e concebido com base nas resoluções vigentes à época de sua regulamentação, ou seja, a resolução CNE/CP 01/2002 e CNE/CES 07/2004, conforme se depreende (UNIR, 2012, p. 12):

O Currículo aqui apresentado propõe, a partir dos novos paradigmas presentes nas diretrizes curriculares nacionais promover uma formação dinâmica de seus acadêmicos com uma perspectiva integradora entre teoria-prática, habilidades e competências, formação básica e formação profissionalizante.

De acordo com o PPP estudado, ilustramos por meio de um mapa conceitual a organização do currículo formal (escrito), vejamos: 
Esquema 1 - Organização curricular do Projeto Político Pedagógico do curso de Licenciatura em Educação Física da UNIR

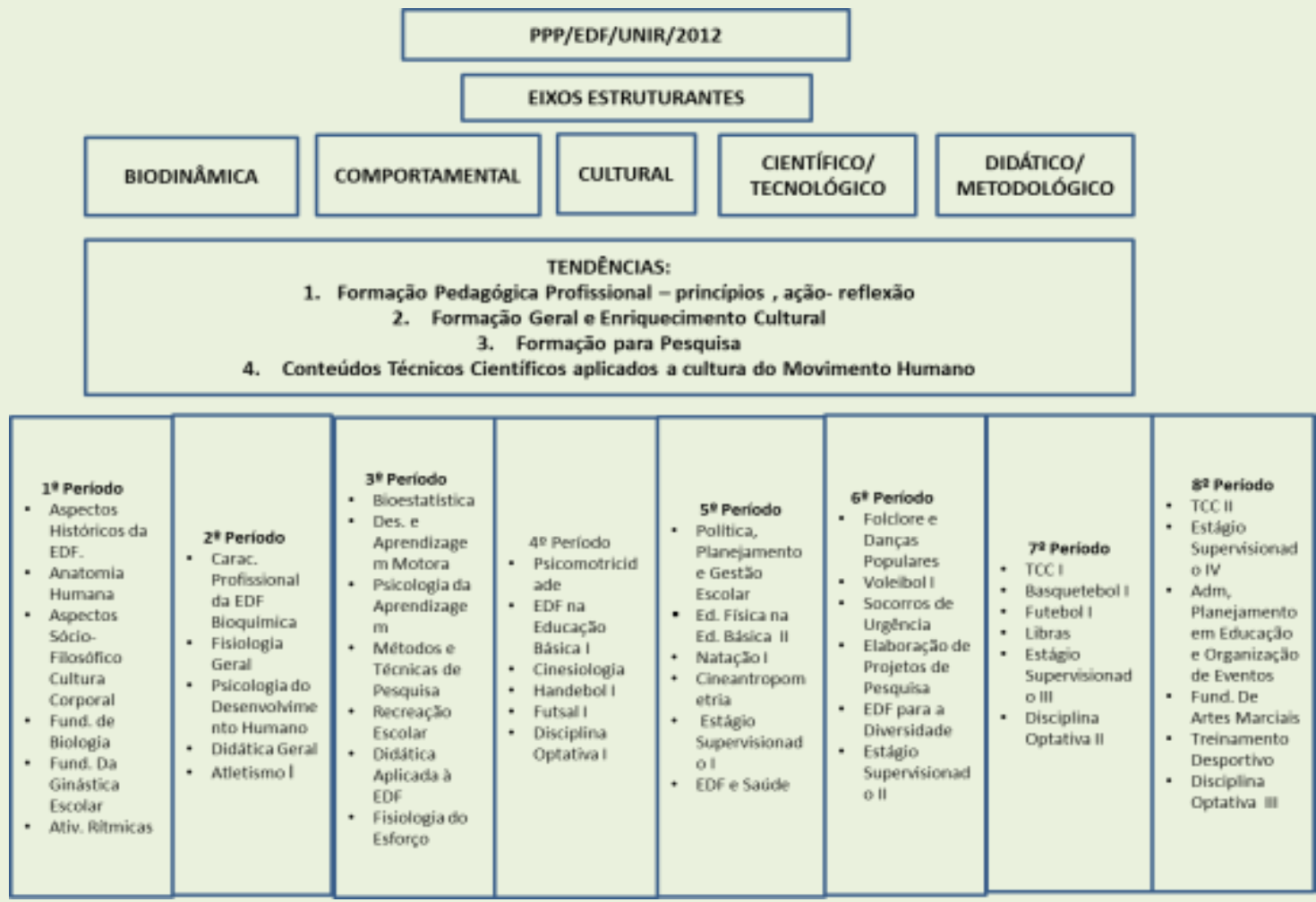

Fonte: Figura elaborada pelo autor, com base no PPP (UNIR, 2012).

Ao examinar com atenção a ilustração acima, bem como o PPP do curso estudado, verificamos que no texto, a matriz curricular foi escrita e organizada em forma de "eixos temáticos que se articulam entre si promovendo a unidade entre as tendências e as disciplinas, rompendo com a fragmentação e a linearidade" (UNIR, 2012, p. 13).

Verificamos, ainda, que o este documento possui duas áreas de aprofundamento: 1. Ênfase em Educação Física e a promoção da Educação e 2. Ênfase em Educação Física e a promoção da Saúde (UNIR, 2012, p. 14).

Reconhecemos, portanto, a procedência de organização metodológica e didático-pedagógica no PPP, pois há razoável consenso entre as resoluções supracitadas se a organização da matriz curricular do curso estudado. Contudo, concordamos com D'Ávila (2013, p. 24). 
As DCN estão longe de representar o ideal em termos de regulamentação da formação docente para a educação básica. No seu interior podemos observar um forte acento sobre a formação técnico-profissional. Segundo Veiga (2002, p. 72), é uma formação "baseada no fazer para o aprendizado do que se vai ensinar [...] Essa perspectiva de formação centrada nas competências é restrita e prepara, na realidade, o prático, o tecnológico, isto é, aquele que faz mas não conhece os fundamentos do fazer".

Essa afirmação expressa, de fato, que "os currículos nos cursos superiores de Educação Física refletem, igualmente, uma ideologia em seus programas [...], com outros inúmeros fatores de ordem social, econômica, política e estrutural" (ANGULSKI, 2012, p. 43).

Não há que se alimentar ilusões. Se a organização curricular do PPP pesquisado expressa os fatores e exigências das DCN, isso apenas indica que

É preciso organizar o currículo de forma a proporcionar uma visão ampla e atual de ciência, numa relação aberta que permita estabelecer conexões fortes e articulações conceituais não só apenas dos saberes de referência (científicos) como em outros campos. A integração por meio de contribuição de campos de saberes interdisciplinares pode ter por referência as disciplinas científicas. Organizar o currículo em tono de ideias básicas ou em torno de problemas relevantes requer abordagens interdisciplinares (VEIGA, 2004, p. 67).

Em síntese, as abordagens aqui desenvolvidas remetem ao início dessa reflexão que coaduna com que Veiga (2004) e D'Ávila (2013), quando destacam a integração dos saberes constituídos na formação inicial numa perspectiva interdisciplinar entre o currículo formal e o real. Este modo de ver a organização e implementação do currículo para a formação do professor de Educação Física está estreitamente vinculado ao trabalho articulado pela indissociabilidade da relação teoria-pratica, consolidado pela construção de competências profissionais do educador físico em uma perspectiva de integralização dos saberes necessários à docência, ou seja, saberes de experiência, os conhecimentos específicos da matéria e os saberes pedagógicos (PIMENTA, 2012b).

Ao iniciarmos o diálogo entre os saberes docentes e a relação teoria prática no estágio curricular supervisionado, tomamos o cuidado de 
esclarecer o papel constitutivo desses aportes formativos, situando no conjunto dos saberes e da relação teoria-prática no estágio, esclarecendo seu papel constitutivo na formação do professor em Educação Física. Consideramos que não é possível viabilizar o estágio curricular supervisionado sem os saberes docentes mobilizados durante todo $\mathrm{O}$ processo de formação, sejam eles teóricos ou práticos, logo o mesmo não pode ser tratado isolado da legislação que o baliza.

Dessas considerações, temos como referência de saberes, os trazidos por Tardif (2013) que os descreve como saberes disciplinares, curriculares, e experienciais, acrescentando que "os saberes são elementos constitutivos da prática docente" (TARDIF, 2013, p. 39). Ainda ressaltamos ser majoritário que o estágio curricular supervisionado no curso de Educação Física acompanhe as mudanças que ocorrem durante sua realização para que não perca durante o processo da formação dos futuros professores as diretrizes que direcionam a sua prática, sejam pedagógicas, metodológicas ou legais. Desde essa concepção, concordamos com Bianchi, Alvarenga e Bianchi (2009, p. 13) quando afirmam que:

É necessário que as instituições e seus professores encarregados do estágio analise e acompanhe as mudanças das leis tendo como exemplo atual lei $n^{\circ} 11.788$, aproveitando a oportunidade de conduzir alunos para a importância desse conhecimento, não somente nos estágios como também em sua conduta cidadã.

Ao compulsarmos a lei 9.394/96, observa-se que o artigo 82 institui que os sistemas de ensino estabelecerão as normas de realização de seus estágios em suas jurisdições, direcionando a lei federal n 11.788 de 2008:

Art. 1으 Estágio é ato educativo escolar supervisionado, desenvolvido no ambiente de trabalho, que visa à preparação para o trabalho produtivo de educandos que estejam frequentando 0 ensino regular em instituições de educação superior, de educação profissional, de ensino médio, da educação especial e dos anos finais do ensino fundamental, na modalidade profissional da educação de jovens e adultos.

$\S 1$ ○ O estágio faz parte do projeto pedagógico do curso, além de integrar o itinerário formativo do educando. 
$\S 2 \circ$ O estágio visa ao aprendizado de competências próprias da atividade profissional e à contextualização curricular, objetivando o desenvolvimento do educando para a vida cidadã e para o trabalho.

Art. 2ㅇ...]

$\S$ lo Estágio obrigatório é aquele definido como tal no projeto do curso, cuja carga horária é requisito para aprovação e obtenção de diploma (BRASIL, 2008).

Esse comando legal enfatiza os tipos de estágios classificando-os em obrigatório e remunerado. Daremos enfoque ao estágio curricular obrigatório para formação do professor, trazendo a lume a discussão do desenvolvimento profissional vinculado à aprendizagem de competências rigorosamente apresentada na citação acima.

Resta inconteste que a maioria dos cursos Educação Física ainda estão funcionando baseados na resolução CNE/CP 01/2002, a qual instituiu a DCN para formação de professores da Educação Básica. Contudo se faz necessário traçarmos um paralelo com a configuração dada pela nova Resolução CNE/CP 02/2015, observa-se que ao ser instituída tece considerações sobre a formação e principalmente sobre o estágio e apresenta:

Art. 13. Os cursos de formação inicial de professores para a educação básica em nível superior, em cursos de licenciatura, organizados em áreas especializadas, por componente curricular ou por campo de conhecimento e/ou interdisciplinar, considerando-se a complexidade e multirreferencialidade dos estudos que os englobam, bem como a formação para o exercício integrado e indissociável da docência na educação básica, incluindo o ensino e a gestão educacional, e dos processos educativos escolares e não escolares, da produção e difusão do conhecimento científico, tecnológico e educacional, estruturam-se por meio da garantia de base comum nacional das orientações curriculares.

[...]

$\S 6^{\circ} \mathrm{O}$ estágio curricular supervisionado é componente obrigatório da organização curricular das licenciaturas, sendo uma atividade específica intrinsecamente articulada com a prática e com as demais atividades de trabalho acadêmico (BRASIL, 2015, p. 13).

Dessa forma, o estágio curricular supervisionado é a atividade docente vivenciada pelo futuro professor no chão da escola, local onde ocorre a relação entre os saberes das disciplinas com situações reais na escola encadeada pela relação teoria-prática. Nesse caso, assume os 
saberes professores como fundamental para o processo da formação e prática docente. Tais características levam ao reconhecimento do protagonismo do estágio no processo de formação de professores. Outra característica merecedora de atenção refere-se ao estágio supervisionado como um componente curricular que mobiliza todos os outros componentes curriculares.

Asseveram Pimenta e Lima (2011, p. 34) que,

\begin{abstract}
Alertam que os currículos de formação de professores têm se constituído em um amontoado de componentes curriculares que se efetivam no cotidiano da formação inicial isolados entre si, e afirma que por vezes essa "Contraposição entre teoria e prática não é meramente semântica, pois se traduz em espaços desiguais de poder na estrutura curricular".
\end{abstract}

Com efeito, enquanto constatamos em Parente e Mattos (2015) que o estágio é capaz de gerar aprendizagens significativas e interdisciplinares que contribuem para o fazer docente, encontramos em Pimenta e Lima (2011) a problemática dos cursos estarem se constituindo por componentes curriculares isolados entre si. Ao que podemos observar existe um paradoxo entre o que poderia ser e o que realmente é.

Destarte o poder que a estrutura curricular apresenta no processo de formação do professor, trazemos em tela o que dizem os documentos legais sobre a implementação do estágio curricular supervisionado para os cursos de licenciatura, em especial, o curso de Educação Física, com a finalidade de verificar como o PPP do curso de EDF/UNIR contempla a formação evidenciada no estágio curricular supervisionado.

Ressalte-se que a Resolução CNE/CES 07/2004 também albergou seu texto nessa mesma esteira de pensamento. Ao que demonstra, esses dispositivos legais apresentam o estágio curricular supervisionado para os cursos de licenciatura. Na área de Educação Física, o artigo 10, $\S 2^{\circ}$ apresenta claramente a indissociabilidade teoria-prática, explicitando ainda a competência, ou um conjunto dessas como ponto nuclear para formação desse docente: 
Art. 10 - A formação do graduado em Educação Física deve assegurar a indissociabilidade teoria-prática por meio da prática como componente curricular, estágio profissional curricular supervisionado e atividades complementares.

Parágrafo $2^{\circ}$ - $O$ estágio profissional curricular representa um momento da formação em que o graduando deverá vivenciar e consolidar as competências exigidas para o exercício acadêmico-profissional em diferentes campos de intervenção, sob a supervisão de profissional habilitado e qualificado, a partir da segunda metade do curso.

I. No caso da Instituição de Ensino Superior optar pela proposição de núcleos temáticos de aprofundamento, como estabelece o Art. $7^{\circ}, \S$ $1^{\circ}$ desta Resolução, $40 \%$ da carga horária do estágio profissional curricular supervisionado deverá ser cumprida no campo de intervenção acadêmico-profissional correlato.

$\S 1^{\circ}$ desta Resolução, $40 \%$ da carga horária do estágio profissional curricular supervisionado deverá ser cumprida no campo de intervenção acadêmico-profissional correlato.

Ante ao explicitado pelas DCN nos artigos acima, é necessária cautela, já que "ao colocar as competências como núcleo central dos currículos de formação de professores, podem provocar redução dos professores a consumidores de cursos, em busca de permanente atualização de competências" (PIMENTA; LIMA 2011, p. 87).

No bojo dessas contradições pré-determinadas pelos dispositivos legais supracitados, insurge estudar o PPP do curso de Educação Física da UNIR, com o escopo de verificar como está estruturado o estágio curricular supervisionado do curso em comento (UNIR, 2012, p. 44-46):

O Estágio é considerado atividades de aprendizagem profissional proporcionadas ao estudante, pela sua participação em situações reais de vida e trabalho de seu meio. Trata-se de um componente curricular para enriquecimento didático, curricular, científico e cultural, sendo além de obrigatório, também de vital importância na formação profissional de docentes, estando demarcado na LDB. Pareceres CNE/CP 009/2001, CNE/CP 21/2001, CNE/CP 27/2001 e CNE/CP 28/2001.

[...]

Organização Funcional - De acordo com o Parecer 138/2002 CES/CNE, este deverá ser realizado de maneira supervisionada, a partir da leitura da realidade, oferecendo ao futuro professor um conhecimento do real em situação de trabalho, constatando as possibilidades de realização das competências exigidas na prática profissional.

Para que os acadêmicos realizem o estágio supervisionado com qualidade, prevê-se a criação de uma Comissão Geral de Estágios Curriculares para gerenciar suas atividades, a qual será gerida por um Coordenador e fiscalizadas e orientadas por quantos 
colaboradores se fizerem necessário, que funcionaram como Supervisores de Campo divididos nas categorias: Supervisor Acadêmico - obrigatoriamente professor do DEF - UNIR, e Supervisor Local - obrigatoriamente atuante no local de desenvolvimento do estágio.

Extrai-se dessa citação, que há previsão de criação de uma Comissão Geral de Estágios Curriculares para gerenciar as atividades, a qual será composta por um docente coordenador e docentes supervisores dos estágios. Veiga (2004, p. 113) destaca que a supervisão do estágio terá "a incumbência de: coordenar e supervisionar os estagiários; orientar os futuros professores no tocante ao desenvolvimento teórico-prático do estágio e a elaboração do projeto do estágio e relatório; determinar horários reservados, especificamente, para essas funções".

Outro aspecto, em relação a estágio curricular supervisionado do curso pesquisado que merece atenção, são os campos de atividades do estágio, que são apresentados no documento oficial (UNIR, 2012, p. 47):

Campos de Estágio: As atividades de Estágio Supervisionado serão desenvolvidas considerando os mecanismos jurídicos vigentes, e se dará em consonância com os eixos norteadores do curso (Biodinâmica, Comportamental, Cultural, Científico-tecnológico e Didático-pedagógico), sendo facultado ao acadêmico, realizá-lo em qualquer campo de estágio onde se desenvolvam ações pertinentes aos eixos supracitados, tais como: clubes, associações, ONG's, academias, laboratórios, hospitais, etc, desde que aprovado pela Chefia do Departamento, devendo o aluno optar por dois dos eixos acima mencionados para cumprir oitenta (80) horas em cada um deles, totalizando as cento e sessenta (160) horas preconizadas. Em ambas situações, os campos de estágio devem apresentar como requisitos: a) Comprovada idoneidade e reconhecida excelência de qualidade; b) Corpos docente e administrativo com reconhecida competência profissional, que ofereça efetivas condições para a experiência docente compartilhada; c) Infraestrutura física e material com condições pedagógicas para o desenvolvimento dos projetos de estágio; d) Aceitação das normas que disciplinam o estágio do referido curso; e) Disponibilidade da equipe diretiva e do corpo docente para supervisão específica, apreciação do trabalho de estagiário e trabalho conjunto com o supervisor de campo de estágio.

Com base nessa citação, em uma primeira análise é possível perceber que as atividades do estágio supervisionado do curso estudado são fundamentadas pelos mecanismos jurídicos vigentes e estruturados de 
acordo com os eixos norteadores do curso, facultando ao acadêmico e futuro professor realizá-lo em campos que tenham pertinência com os eixos retro mencionados. Esse ponto merece atenção, pois, na redação, o documento apresenta como campo de estágio locais como: "clubes, associações, ONG's, academias, laboratórios, hospitais, e outros diversos lugares correlatos" (UNIR, 2012).

Os campos de estágios mencionados no documento oficial são de atuação do bacharel e não do licenciado. Cabe ao licenciado um perfil profissional com atuação na Educação Básica, Veiga (2004, p. 113) infere que "o estágio no curso de formação de professores será realizado em locais que assegurem a participação efetiva do aluno em atividades relacionadas diretamente com a orientação acadêmica do curso".

Compreendemos que talvez tenha havido um equívoco na redação do documento oficial com relação ao campo de estágio. Compulsando a matriz curricular do curso de Educação Física da Unir, em uma análise mais acurada, verificamos que os estágios estão distribuídos a partir da segunda metade do curso, ou seja, tem início no $5^{\circ}$ semestre, ficando assim distribuídos: Estágio - I educação infantil; Estágio || no ensino fundamental (anos inicias do $1^{\circ}$ ao $5^{\circ}$ ); estágio III ensino fundamental (anos finais do $6^{\circ}$ ao $9^{\circ}$ ) e por último 0 estágio IV com a vivência no ensino médio e EJA. Esses campos de estágios possuem relação direta com a atuação profissional do licenciado em Educação Física no mercado de trabalho na educação Básica.

Ao estudarmos o PPP ora pesquisado, verificamos que carrega consigo as expectativas das DCN ao qual foi norteadora e dos dispositivos legais vigentes, desconsiderando que esse documento vai muito além dos mecanismos jurídicos citados acima. Concordamos com Veiga (2004) em sua proposta para construção do PPP/PPC, quando enfatiza que:

O projeto representa o movimento de oposição contra a homogeneidade, fragmentação e a hierarquização do cotidiano acadêmico. Representa, portanto, a luta contra o homogêneo, o repetitivo, o alienado, o alienante, o fragmentado. Isso significa que estão abertas muitas vias para uma melhor organização do trabalho 
pedagógico. E como contributo para o esclarecimento da concepção do projeto como possibilidade e como movimento de resistência ao cotidiano programado e instituído (VEIGA, 2004, p. 78).

Diante dessa constatação, não seria crível que as IES, ao estruturarem seus projetos político-pedagógicos para os cursos superiores de formação de professores de Educação Física, refletissem igualmente as ideologias dominantes pré-estabelecidas pelas DCN. É importante que o PPP considere outros diversos fatores de ordem social, político, econômico e cultural.

\section{O CURRÍCULO E O ESTÁGIO CURRICULAR SUPERVISIONADO A PARTIR DAS VOZES DOS DOCENTES E DISCENTES DEF/UNIR}

Para verificar se o currículo escrito também se efetiva no dia-a-dia da formação inicial, se faz necessário analisarmos a seguir o currículo real, vivido pelos sujeitos que fazem parte do processo formativo, ou seja, professores e alunos.

Neste recorte trazemos duas dimensões: Na dimensão 1. Docentes, onde foram pesquisados dois: O Professor Coordenador e Chefe do DEF/UNIR; e o Professor Orientador dos Estágios, codificados respectivamente pelas siglas (PCC) e (PE). Na dimensão 2. Discentes, estes foram codificados pela letra $A$, seguido do numeral de 1 a 14 . OS dados foram analisados a partir de duas categorias: Categoria 1. Currículo real (percebido/vivido) e 2. Saberes docentes e a relação teoria-prática no estágio curricular supervisionado.

\subsection{Categoria 1 - Currículo Real (vivido)}

Essa categoria de estudo depreende-se da seguinte questão: Como está estruturado o currículo do curso de Educação Física da UNIR, levando em conta os discursos dos docentes e discentes? Os dados coletados emergiram incialmente a partir do conhecimento que os alunos têm sobre os documentos que norteiam a formação inicial e, especificamente, as que 
subsidiam a licenciatura em Educação Física. Perguntado aos pesquisados se conhecem o PPP do curso de Educação Física da UNIR? 64\% responderam que conhecem o PPP do curso; $36 \%$ não conhecem.

Esse resultado suscita outra indagação, qual seja: Quais dos documentos a seguir serviram de base para a construção do PPP do curso de EDF da UNIR? As respostas estão ilustradas no gráfico 1:

Gráfico 1 - Percepção dos discentes acerca dos documentos legais do PPPEDF/UNIR

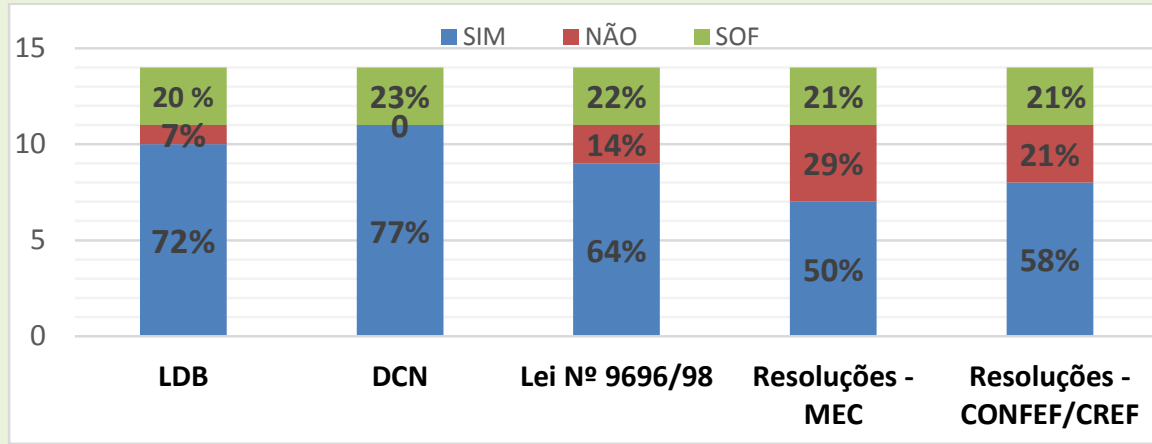

Fonte: Questionário de pesquisa de campo, 2014.

Esses resultados, ao que parece demonstram que os pesquisados, ainda que subjetivamente, acreditam que tanto a LDB como as DCN serviram de base para construção do PPP do curso pesquisado. O percentual foi superior a 70\%, o que coaduna como o gráfico 1 que apresenta um percentual de $64 \%$ dos sujeitos que disseram conhecer 0 documento oficial do curso.

Além dos dados acima, buscamos investigar quais os aspectos positivos e negativos que as DCN do curso de licenciatura em Educação Física trouxeram para efetivação da formação do professor de EDF/UNIR? Nas respostas, observamos que $50 \%$ dos pesquisados responderam não ter opinião formada sobre o assunto e a outra metade, $50 \%$, opinou e justificou suas respostas, apresentando os pontos positivos e negativos. Nas justificativas, encontramos recorrência nas respostas que apresentaram pontos positivos e negativos, vejamos: 
Pontos positivos: "1. fixou matérias específicas (A6); 2. formação ampla do acadêmico $(G) ; 3$. aprofundamento e atuação na área escolar (A4, A9, A12)".

Pontos negativos: "1. Confusão na área de atuação - ter desmembrado em duas áreas (A3, A6); 2. tornar limitado o trabalho apenas na escola (A4, A8, A9, A12); 3. não poder atuar na área esportiva (A9)" (QUESTIONÁRIO DE CAMPO, 2014).

No turno, os resultados apontados pelos discentes pesquisados, a partir de suas justificativas, denotam que, mesmo percebendo a especificidade da formação no curso de licenciatura em Educação Física para atuar na Educação Básica, sentem-se tolhidos em relação ao campo de atuação profissional.

Para encaminhar as vozes dos professores pesquisados, trazemos Palma, Oliveira e Palma (2008, p. 33), que consideram ser "importante que os docentes apropriem-se de todos os conhecimentos possíveis e que, por intermédio deles, elaborem matrizes curriculares a ponto de propiciarem avanços pedagógicos palpáveis e úteis ao momento histórico que estejam vivendo". Nesse sentido, perguntamos aos docentes: Que/Quais documentos legais serviram de base para construção PPP do curso de Educação Física da UNIR? Quanto a isso, responderam:

PCC: "Os documentos legais aí eu me lembro lá no início dessa reformulação, foram exatamente às orientações do MEC, as DCN e a legislação daquele momento, foram as Diretrizes Nacionais e do MEC. Isso você pode consultar diretamente no PPP com mais detalhes, também recorreu e teve também como base outros PPP de outras IES" (ENTREVISTA, 2014).

PE: "Os currículos anteriores que foram analisados, e algumas normas que foram estabelecidas com as disciplinas que não poderiam estar contidas na Licenciatura foram excluídas por causa das novas disciplinas".

"Nós fizemos, pegamos tudo que nós achávamos que era bom, de positivo nos currículos passados. Eu estive a frente desse processo durante algum tempo, nós pesquisamos bastante nas instituições do Ensino Superior para ver como eles chegavam a esse ponto de ter esse bom profissional. Nós tivemos algumas barreiras que não depende somente de nós" (ENTREVISTA, 2014).

Como se pode observar, os docentes pesquisados informaram em seus discursos que, na reformulação do PPP, os documentos legais utilizados 
foram: as DCN, orientações e pareceres do MEC, os currículos anteriores do próprio curso e PPC de outras IES. É louvável que esses professores tenham revelado sua participação na reformulação do PPP, pois demonstra o comprometimento com o curso e com a instituição formadora. Segundo Stenhouse (1991 apud CONTRERAS, 2012, p. 254) afirma que:

\begin{abstract}
Não há desenvolvimento do currículo sem desenvolvimento do professor, é reflexo fiel da mudança de mentalidade que esta visão do currículo significava, associada ao papel fundamental dos professores: são apenas os professores que, em última instância, podem realizar um ensino melhor, e são eles, portanto, que devem gerar e desenvolver currículos melhores.
\end{abstract}

Isso significa que o PPP nos cursos de formação de professores não pode ser pensado em uma perspectiva individualista, como se fosse apenas um documento pessoal, sem reconhecer a sua institucionalidade formal que, de certa forma, indica a profissionalização do futuro docente a partir de uma concepção coletiva e democrática. Essa consciência faz com que as decisões sejam para conduzir e efetivação da matriz curricular. Nesse sentido, realizamos a seguintes pergunta: Como o senhor(a) percebe a efetivação do Currículo do curso de Educação Física/UNIR a partir das disciplinas (desenho curricular) para o processo de formação do licenciado atuar na Educação Básica?

Em suas respostas, os sujeitos pesquisados afirmam que o curso de licenciatura em Educação Física da Universidade Federal de Rondônia atende substancialmente a formação dos professores. Afirmaram, ainda, que essa nova matriz curricular "grade", apesar da carga horária excessiva (PCC), foi muito bem trabalhada e discutida por todos os docentes do DEF/UNIR. O Professor (PE) acredita que esse PPP, a partir do desenho curricular, vá formar bons profissionais. 


\subsection{Categoria 2 - Saberes Docentes e a relação teoria-prática no Estágio Supervisionado}

A tarefa central dessa categoria é analisar que saberes docentes estão evidenciados na relação teoria-prática no estágio curricular supervisionado no curso de EDF/UNIR. A relação que os futuros professores mantêm com os saberes, oriundos das disciplinas cursadas durante a sua formação, constitui mecanismos que podem ser legitimados por eles, durante o estágio curricular supervisionado. Ao reconhecermos a importância desses saberes, realizamos a seguinte pergunta aos pesquisados: As competências estabelecidas no PPP do curso de EDF/UNIR contemplam a formação de um perfil profissional capaz de articular os saberes teóricos com sua prática profissional na escola?

Nas respostas, a maioria dos sujeitos pesquisados representados pelo percentual de $86 \%$ acreditam que as competências estabelecidas no PP de EDF/UNIR para formação do perfil profissional é capaz de articular os saberes teóricos com sua prática profissional na escola, $14 \%$ responderam parcialmente. Embora os resultados apresentados tragam a parcialidade, podemos observar que todos os pesquisados já experimentaram essa articulação entre os saberes teóricos e práticos, visto que nenhum deles acusou a alternativa que sugere a negação dessa articulação entre teoria e prática, conforme a justificativas constantes no quadro a seguir:

Quadro 1 - Justificativas dos discentes acerca das competências estabelecidas no PPP capaz de articular os saberes teóricos com sua prática profissional na escola.

\begin{tabular}{|c|c|l|}
\hline Sujeitos & Respostas & \multicolumn{1}{|c|}{ Justificativas } \\
\hline A1 & SIM & $\begin{array}{l}\text { "mesmo sabendo que algumas situações "lidas", não serão } \\
\text { vivenciadas na escola, porém é possível acontecer e temos a } \\
\text { obrigação de contorna-las." (sic) }\end{array}$ \\
\hline A2 & SIM & $\begin{array}{l}\text { "aumento da capacidade de atuação conciliando a teoria e a } \\
\text { prática" (sic) }\end{array}$ \\
\hline A3 & SIM & $\begin{array}{l}\text { "A mobilização e conscientização dos professores tem ajudado } \\
\text { bastante a relacionar teoria e prática." (sic) }\end{array}$ \\
\hline A4 & SIM & $\begin{array}{l}\text { "Porque já estamos no estágio e temos uma noção, o que } \\
\text { acontece em relação a realidade da escola com a teoria e as } \\
\text { matérias para trabalhar" (sic) }\end{array}$ \\
\hline
\end{tabular}




\begin{tabular}{|c|c|c|}
\hline A5 & $\begin{array}{l}\text { PARCIAL- } \\
\text { MENTE }\end{array}$ & $\begin{array}{l}\text { "Alguns acontecimentos ocorridos no estágio pode solucionar } \\
\text { problemas, tendo um conhecimento prévio do fato" (sic) }\end{array}$ \\
\hline A6 & SIM & $\begin{array}{l}\text { "a aplicabilidade torna-se simples se a matéria é bem assimilada" } \\
\text { (sic) }\end{array}$ \\
\hline A7 & SIM & $\begin{array}{l}\text { "pois o curso oferece uma grade curricular bem extensa, } \\
\text { oferecendo um excelente aprendizado para o aluno". (sic) }\end{array}$ \\
\hline A8 & SIM & $\begin{array}{l}\text { "Teoria muitas vezes não é aplicada junto com a prática, mas na } \\
\text { aula consegue alcancar muitos objetivos" (sic) }\end{array}$ \\
\hline A9 & SIM & $\begin{array}{l}\text { "você estudando a teoria e depois por em prática é o que ajuda } \\
\text { a ter experiência. Sinto que consigo sim relacionar teoria com a } \\
\text { prática em algumas áreas" (sic) }\end{array}$ \\
\hline A10 & SIM & $\begin{array}{l}\text { "tudo que aprendemos na teoria, podem ser vistas na prática, e } \\
\text { como isso engradecendo ainda mais o conhecimento ...]" (sic) }\end{array}$ \\
\hline Al1 & SIM & Não justificou! \\
\hline $\mathrm{A} 12$ & SIM & $\begin{array}{l}\text { "se você obteve o conhecimento teórico, distante da prática é so } \\
\text { aperfeiçoar o conhecimento" (sic) }\end{array}$ \\
\hline A13 & SIM & $\begin{array}{l}\text { "em sua grande maioria as disciplinas são bem ministradas com um bom } \\
\text { embasamento teórico, seguido de aulas práticas na turma, em escolas, } \\
\text { ou seja, teoria-laboratório-prática." (sic) }\end{array}$ \\
\hline A 14 & $\begin{array}{l}\text { PARCIAL- } \\
\text { MENTE }\end{array}$ & $\begin{array}{l}\text { "algumas disciplinas são facilmente relacionadas entre teoria e prática, } \\
\text { mas lá outras em que não vemos uma relação tão próxima com a } \\
\text { atuação docente." (sic) }\end{array}$ \\
\hline
\end{tabular}

Fonte: Questionário de pesquisa de campo, 2014.

Por meio das respostas advindas do questionário de campo, os resultados tabulados no quadro acima evidenciam que os discentes, em sua grande maioria, ou seja, $86 \%$, percebe que as competências profissionais estão sendo trabalhadas articulando os saberes teóricos e práticos relacionando-os com o mercado de trabalho. Parente e Mattos (2015, p. 64), discutindo sobre o estágio supervisionado, enfatizam "A preocupação com os vínculos entre práticas docentes e as teorias educacionais, mas comumente denominadas "relação teoria-prática", ocupa grande parte das discussões na área de educação, em especial, naquelas relativas à formação de professores".

Com relação aos docentes, iniciamos, com 0 seguinte questionamento: Quais as competências estabelecidas no PPP do curso de EDF/Unir comtemplam a formação de um perfil profissional capaz de articular os saberes teóricos com sua pratica profissional na escola? Assim se manifestaram os professores à questão apresentada:

PCC: Na construção do PPP foi recomendado a competências e habilidades necessárias determinadas pelas DCN, isso foi levado em 
consideração. Hoje isso está sendo um processo, nós estamos avaliando o curso agora e estamos vendo que precisamos refazer alguns ajustes. Então assim, as competências e as habilidades para o foco da Licenciatura estamos mais atentos, não só o que está no papel, mas na prática, nós professores estamos mais preocupados com essa competência profissional dos nossos alunos.

Uma coisa hoje que nós estamos experimentando no curso é levar para o campo prático, sair da teoria e levar para a prática. Esse cruzamento teoria e prática estão permitindo o aluno ter uma visão mais real, mais própria do ambiente onde ele vai trabalhar. [...]

PE: Ter conhecimento do que é a responsabilidade do que é o ensinar, ele tem que abraçar esse conhecimento, ele tem que ler, ele tem que buscar a pesquisa, ele tem que estar avaliando para que realmente através desse conhecimento possa está fazendo um trabalho bem competente como a gente quer, até para que o próprio profissional de educação física tenha um melhor reconhecimento dentro da própria da sociedade (ENTREVISTA, 2014).

Extrai-se, a partir desses discursos, a dinamicidade das relações entre professor e aluno ocorrida na prática do acadêmico no estágio curricular supervisionado. Isso passa a ser um mediador entre os saberes teóricos e práticos. Percebemos, ainda, uma compreensão da importância de articular o que está escrito formalmente no PPP e as atividades práticas do curso. Parente e Mattos (2015), ao tratar sobre o estágio supervisionado dos profissionais da educação, defendem que:

O estágio seja protagonista na formação dos profissionais da Educação. O que significa? Que ele seja reconhecido como espaço, momento, condição e oportunidade para que a formação do professor seja consolidada. É por meio do estágio que são criadas (ou deveriam ser) condições para que o aluno em formação visualize os espaços em que irá atuar e se reconheça como sujeito desses espaços (PARENTE; MATTOS, 2015, p. 63).

Assim, a busca pela compreensão da relação da prática profissional, vivenciada na escola articulada pelos saberes teóricos no estágio curricular supervisionado presentes nas competências estabelecidas no PPP, reforça a perspectiva em investigar junto aos docentes pesquisados que saberes são indispensáveis para a formação do licenciado em Educação Física atuar como professor de Educação Básica?

A partir das respostas dos entrevistados, foi possível verificar a validação dos saberes docentes para formação do licenciado em 
Educação Física da UNIR, segundo suas concepções. O professor (PCC) "entende como indispensáveis os diversos saberes, tais como: saber filosófico, saberes biológicos, saberes do corpo físico como atividade física e saúde, saberes pedagógicos percebidos no planejamento e o saber científico". Apresenta, ainda, saberes a partir de conteúdos transversais "como meio ambiente" (PCC). O Professor (PE) discorre acerca dos saberes específicos e pedagógicos, fazendo alusão à importância de se planejar, dentro da perspectiva do plano de ação, em conjunto com o professor supervisor do estágio da própria escola. Durante as vivências práticas nos estágios, aponta algumas disciplinas específicas, como "metodologia da ginástica, primeiros socorros e as de cunho esportivo" (ENTREVISTA, 2014).

Esses docentes enfatizam os saberes pedagógicos como um ponto forte no processo de formação do licenciado do curso ora pesquisado. Constatamos, ainda, que os saberes emergiram em decorrência das experiências vivenciadas em práticas escolares durante $\mathrm{O}$ processo de formação inicial. Em adendo a esse contexto procuramos saber sobre a estrutura do estágio curricular supervisionado a fim de verificar como acontecem os percursos educativos no campo de atuação profissional do futuro professor de Educação Física, visto que essa organização responsabiliza-se pelas rotinas das atividades práticas. Cumpre, todavia, analisar: Como está estruturado o Estágio Curricular Supervisionado? E qual o campo de atuação? A partir daí, foram extraídas as seguintes respostas:

PCC: Na grade nova há uma preocupação onde eles já estão passando nas disciplinas básicas relacionadas mais com as práticas da educação física na escola. Já passando por ministrar as aulas práticas, fazendo um planejamento, já preenche um registro de campo, discute essa prática lá. Talvez quem vai te responder com mais propriedade é o professor do estágio [...] deveria trabalhar com uma equipe que ainda não tem trabalhado de forma articulada e tem sobrecarregado em cima de uma ou duas pessoas. Esse acompanhamento do estágio supervisionado torna isso um ponto negativo. [...].

PE: [...] Nós temos um convenio coma SEDUC, assim como temos convenio com a SEMED, [...]. A coordenação do Estágio (EU) selecionamos algumas escolas, e a gente ver nessas escolas, a questão da estrutura, o profissional de educação física [...]. Esses 
alunos que estão matriculados que vão iniciar o estágio, irão levar um documento (Ofício) que sai da coordenação de estágio apresentando esse aluno, paralelamente a esse ofício a gente leva um termo de compromisso que é uma exigência não só da instituição, como também do próprio Ministério de Trabalho, o seguro de vida obrigatório, enviamos os nomes desses alunos para um setor aqui da Universidade que providencia a cobertura, se por ventura surgir algum tipo de problema. [...]

O importante é que o acadêmico dentro da escola cumpra aquela carga horária, no caso hoje os Estágios são de 100 horas cada. 0 Estágio I (Infantil), o Estágio II (Ensino Fundamental do $1^{\circ}$ ao $5^{\circ}$ ano), o Estágio III (do $6^{\circ}$ ao $9^{\circ}$ ano) e o IV no Ensino Médio, mas alguns grupos trabalham também com a EJA com o Ensino Especial, atendemos também alguns casos especiais como o Hospital de Base que aqui dá essa oportunidade. Nessa carga horária de 100 horas tem uma porcentagem de: observação, participação e Regência" (ENTREVISTA, 2014).

De acordo com as respostas dos professores entrevistados, verificamos que o estágio supervisionado está estruturado por uma matriz curricular em vigor desde 2012 (UNIR, 2012). É possível perceber que a iniciação profissional está sendo privilegiada pelos estágios que possibilitam aprendizagens nas mais diversas situações vivenciadas no campo da instituição escolar na escola de Educação Básica. Entretanto, o estágio curricular do curso pesquisado possui algumas lacunas para serem resolvidas, dentre elas: a falta de articulação dos docentes do departamento, visto que ainda não possui regulamentação/regimento.

Constatamos, nas vozes dos pesquisados, que ainda não existe um reconhecimento do trabalho coletivo pelos docentes que compõem 0 departamento do curso de licenciatura em Educação Física da UNIR. É, no contexto até aqui descrito, que torna-se necessário estimular a participação do colegiado no acompanhamento dos estágios supervisionados a partir do entendimento de Almeida e Pimenta (2014, p. 29) sobre estágio:

Assim entendemos o estágio como um campo de conhecimento que envolve estudos, análise, problematização, reflexão e proposição de soluções para o ensinar e o aprender, e que compreende a reflexão sobre as práticas pedagógicas, o trabalho docente e as práticas institucionais, situados em contextos sociais, históricos e culturais. Nesse sentido, caracteriza-se como mediação entre os professores formadores, os estudantes em curso e os professores das escolas. Em sua realização, esses sujeitos se colocam atentos aos nexos e às relações que se estabelecem e a partir dos

Revista Exitus, Santarém/PA, Vol. 7, № 1, p. 222-253, Jan/Abr 2017. 
quais poderão realizar as articulações pedagógicas e perceber as possibilidades de se realizar pesquisas entre eles, tendo os problemas da escola como fenômenos a serem analisados, compreendidos e mesmo superados.

De posse dessas considerações, é pertinente perguntar aos docentes: O Estágio Curricular Supervisionado influencia na formação que vem sendo dada aos acadêmicos para prática da docência na Educação Básica?

Nas respostas, verificamos que o estágio curricular supervisionado "tem influenciado positivamente no processo de formação do licenciado em Educação Física apesar das fragilidades apontadas na sua essência" (PCC). O entrevistado (PE) por sua vez fez suas considerações relatando como positivo que "essa é a primeira turma nesse formato de estágio presente no currículo novo, o qual já cursou o estágio I e está concluindo o ll. Salienta que esse momento propicia uma vivência maior no campo de atuação e reflexão sobre futuro mercado de trabalho" (PE).

O ponto de partida para essa incursão é trazido por Parente e Mattos $(2015$, p. 67) ao afirmarem que:

\begin{abstract}
Não é mais possível brincar de fazer estágio. Muitas vezes ele tem sido um faz-de-conta para a escola, para o aluno em formação e para o professor que orienta. $O$ professor que orienta nem sempre consegue romper com as supostas amarras dos projetos pedagógicos dos cursos de formação de professores, ou mesmo convencer os seus pares da necessidade de mudança; muitos pares da universidade ainda tratam estágio ora como sobrecarga, peso e castigo, ora como trabalho fácil, sem status de disciplina, como mero processo de orientação, como se a orientação não fosse igualmente atividade docente que exige preparação, planejamento, avalição e muita dedicação.
\end{abstract}

Na dimensão 2. Discentes, verificamos que $100 \%$ dos pesquisados já cursaram os estágios I e II, desencadeia um encaminhamento para buscar respostas a partir da percepção destes sujeitos acerca dessa temática. Para isso, formulamos a seguinte pergunta: Como você percebe a organização do estágio supervisionado para promover a aplicabilidade da teoria na prática? 
Gráfico 2 - Percepção dos discentes sobre a aplicabilidade da teoria-prática no estágio

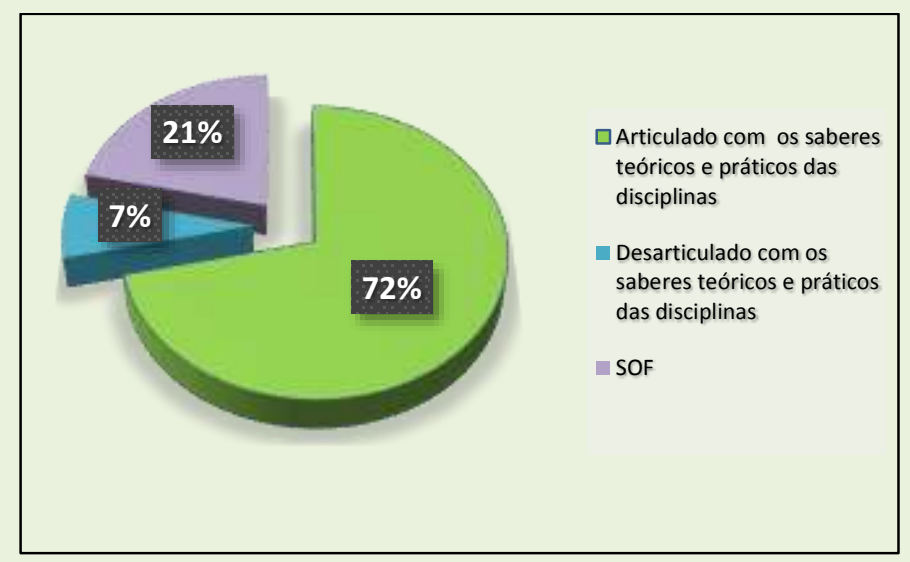

Fonte: Questionário de pesquisa de campo, 2014.

Segundo as justificativas dos pesquisados, verifica-se: "Seguem o mesmo caminho, as disciplinas, professores e a vivência é bem nítida, quando se trata dessa organização. A teoria e a prática andam juntas." (A1), ou mesmo "O relatório do estágio descreve todas as fases: observação, participação e regência, onde os acadêmicos discorrem sobre as atividades desenvolvidas e as dificuldades encontradas". (A13). De modo geral, esses sujeitos assinalaram que o cenário pesquisado tem mobilizado os saberes pedagógicos, assim como os específicos, relacionando-os à prática educativa.

As respostas dos discentes são contempladas por Pimenta (2012a, p. 105) quando defende que: "A atividade teórica é que possibilita de modo indissociável o conhecimento da realidade e o estabelecimento de finalidades para sua transformação. Mas para produzir tal transformação não é suficiente a atividade teórica; é preciso atuar praticamente."

Para investigarmos sobre a influência que o estágio curricular supervisionado tem provocado nos discentes, foi realizada a seguinte pergunta: O estágio curricular supervisionado influencia na formação que vem sendo dada ao acadêmico de licenciatura em Educação para a prática da docência na Educação Básica? As respostas dos sujeitos apontam que $79 \%$ acreditam que o estágio influencia na formação como docente, e $21 \%$ acreditam que influenciam, embora seja parcialmente. 
Esses dados representam um número relevante de sujeitos que afirmam existir a influência do estágio para as suas práticas educativas. $O$ aluno (A3) ressalta que o estágio curricular supervisionado "Influencia, pois é através dele que o profissional consegue conciliar todo 0 aprendizado ministrado pela universidade". Outro pontua que "Sim, pois podemos ver a realidade do professor de Educação Física nas escolas e quais são seus maiores problemas" (A11). A dificuldade encontrada se mostra na justificativa do Aluno (A1) ao revelar sua preocupação com a profissionalização - "Na escola sentiremos as dificuldades de um profissional preparado para contornar as situações problemas". Ao analisarmos os três relatos, podemos afirmar que o último mostra as marcas das contradições de ensino realizadas nos estágios curriculares supervisionados.

Em que pese os limites e as possiblidades dessas influências é preciso examinar o papel do professor/orientador do estágio curricular supervisionado. Visto que "os estagiários deverão contar com a supervisão direta do seu orientador em todos os momentos do estágio que sejam essenciais para a reflexão sobre as observações/investigações realizadas e nos encaminhamentos possíveis e necessários de cada etapa" (BARREIRO; GEBRAN, 2006, p. 104).

\section{CONSIDERAÇÕES FINAIS}

A reflexão suscitada nesta pesquisa encontra-se em consonância com a recente reforma do Ensino Médio proposta pelo governo federal, uma vez que a Educação Física enquanto componente curricular da Educação Básica tem protagonizado discussões no meio acadêmico e político sobre sua permanência e obrigatoriedade nesta etapa de ensino. Dessa forma, ao elegermos como objeto de investigação o estágio curricular supervisionado na formação do professor de Educação Física a partir do currículo, os resultados poderão propor à academia indicadores no sentido de envidar esforços e apontar caminhos para uma formação consistente e articulada com o campo de atuação profissional do licenciado no chão da escola. 
Com relação à organização curricular, constatamos, em síntese, que o curso pesquisado atende aos ditames dos dispositivos legais. O PPP deve ser considerado como um recurso integralizador dos saberes das disciplinas nas situações da prática. Isso significa que a formação do professor de Educação Física se daria vinculada ao contexto de trabalho, permeado por uma ação coletiva dos docentes formadores com 0 fito de articular os diferentes saberes por meio da interdisciplinaridade.

Nesse sentido, cabe destacar as respostas advindas do questionário de campo realizado com os docentes e discentes, onde os resultados evidenciam uma percepção na qual as competências profissionais estão sendo trabalhadas articulando os saberes teóricos e práticos relacionado com o mercado de trabalho.

Entretanto, nas vozes dos professores pesquisados, o estágio supervisionado possui algumas lacunas para serem resolvidas com relação a sistematização, dentre elas: o regulamento/regimento interno e a falta de articulação dos docentes do DEF/UNIR que ainda não reconhecem a importância do trabalho coletivo. É no contexto até aqui descrito que se torna necessário estimular a participação do colegiado no acompanhamento dos estágios supervisionados, pois este, não se consolida por organismos isolados, essa consolidação depende da integração exercida pelos documentos norteadores, alunos em formação, professores formadores, e gestores do curso.

A organização desse espaço implica na decisão dos futuros professores em "ser ou não ser" um professor. Trata-se de uma proposta de estágio realimentado pelos sujeitos que vivem a teoria e a prática, pela profissão exercida e pelo compromisso com a Educação Básica realizada nos âmbitos escolares.

Assim, os resultados encontrados e as teorias que fundamentam 0 estágio curricular supervisionado na formação do professor de Educação Física, inferem que e a sua viabilização está condicionada principalmente pela indissociabilidade teoria-prática desde os saberes docentes 
trabalhados e percebidos pelo currículo real (vivido), que o mesmo trata-se do lugar em que o futuro professor constrói a sua profissão e o domínio da prática pedagógica nos cotidianos educativos por meio da colaboração universidade/escola.

\section{REFERÊNCIAS}

ALMEIDA, M. I. de; PIMENTA, S. G. Estágio Supervisionado na formação docente: Educação Básica e Educação de Jovens e Adultos. São Paulo: Cortez, 2014.

ANGULSKI, C. M. A disciplina de Historia da Educação Física na formação inicial em Educação Física. In: BOTH, A.; FARIAS, J.; FOLLE, G. O. (org.). Educação Física: formação e regulamentação profissional. Chapecó: Argos, 2012.

BARDIN, L. Análise de Conteúdo. Lisboa, Portugal. ed. 70, LDA, 2009.

BARREIRO, I. M. de F.; GEBRAN, R. A. Prática de ensino e estágio supervisionado na formação de professores. São Paulo: Avercamp, 2006.

BIANCHI, A. C. de M.; ALVARENGA, C.; BIANCHI, R. Manual de orientação: estágio supervisionado. 4. ed. S. Paulo: Cengage Learning, 2009.

BRASIL. Diretrizes Curriculares Nacionais para a formação inicial em nível superior (cursos de licenciatura, cursos de formação pedagógica para graduados e cursos de segunda licenciatura) e para a formação continuada. Brasília, DF: CNE/CP 02/2015.

BRASIL. Diretrizes Curriculares Nacionais para Graduação em Educação Física em nível superior de graduação plena. Brasília, DF: CNE/CP 01. 2002.

BRASIL. Diretrizes Curriculares Nacionais para Graduação em Educação Física em nível superior de graduação plena. Brasília, DF: CNE/CES 07. 2004.

BRASIL. Lei de Diretrizes e Bases da Educação Nacional $\mathbf{n}^{\circ}$. 9394. Brasília: 1996. Disponível em: <http://www.planalto.gov.br/ccivil/LEIS/L9394.htm> Acesso em: jan. 2014.

BRASIL. Lei que dispões sobre estágios para os cursos de licenciatura lei $\mathbf{N}^{\circ}$. 11.788/2008. Disponível em: <wWw.planalto.gov.br/ccivil/LEIS/ L11788>. Acesso em: ago. de 2016.

CONTRERAS, J. Autonomia de Professores. Trad. Sandra Trabusco Valenzuela. 2. ed. São Paulo: Cortez, 2012.

D'ÁVILA, M. C. Docência na Educação Superior: labirintos e saídas na construção da profissionalização docente. In: D'ÁVILA, M. C.; VEIGA, I. P. A (Orgs.). Profissão Docente na Educação Superior. Curitiba - PR: CRV, 2013. 
DOURADO. L. F. Diretrizes Curriculares Nacionais para formação inicial e continuada dos profissionais do Magistério da Educação Básica: Concepções e Desafios. Rev. Educ. Soc., Campinas, v. 36, n 131. P. 299-324, abr-jun., 2015.

LIBÂNEO, J. C. Organização e gestão da escola: teoria e prática. 6. ed. rev. e ampl. São Paulo: Heccus, 2013.

PALMA, A. P. T. V.; OLIVEIRA, A. A. B.; PALMA, J. A. V. Educação física e organização curricular: educação infantil e ensino fundamental. Londrina-PR: UEL, 2008

PARENTE, C. da M. D.; MATTOS, M. J. V. M. O estágio supervisionado na formação dos profissionais da educação. In: PARENTE, C. Da M. D.; VALE, L. E. L. R.; MATTOS, M. J. V. M. (Orgs.). Formação de professores e seus desafios frente às mudanças sociais, políticas e tecnológicas. Porto Alegre: Penso, 2015. p. 63-74.

PIMENTA, S. G. Estágio supervisionado na formação de professores: Unidade teoria e prática. 11 ed. São Paulo: Cortez, 2012a.

PIMENTA, S. G. Saberes pedagógicos e atividade docente. 8. ed. São Paulo: Cortez, 2012b.

PIMENTA, S. G; LIMA, M. do S. L. Estágio e docência. 6. ed. São Paulo: Cortez, 2011 . (Coleção docência em formação - Série saberes pedagógicos).

TARDIF, M. Saberes Docente e Formação Profissional. 15 ed. Petrópolis, RJ: Vozes, 2013.

TOJAL. J. B. Licenciaturas - Novas Diretrizes. In: Revista Educação Física. Setembro, 2015, $\quad \mathrm{n}^{\circ} \quad 57 . \quad$ Disponível em: <http://www.confef.org.br/extra/revistaef/>. Acesso em: 10. out. 2015

UNIR. Projeto Político Pedagógico do curso de Licenciatura em Educação Física da Universidade Federal de Rondônia. 2012. Disponível em: <www.unir.gov.br>. Acesso em: 09 set. 2016.

VEIGA, I. P. A. Educação Básica: Projeto político-pedagógico; Educação superior: projeto político-pedagógico. Campinas, SP: Papirus, 2004. (Coleção Magistério: Formação e trabalho pedagógico)

VEIGA, I. P. A. A escola mudou: que mude a formação de professores. Campinas, SP: Papirus, 2010. (Coleção Magistério: Formação e Trabalho Pedagógico).

Recebido em: Setembro de 2016 Aceito em: Dezembro de 2016 